\title{
Translation of Public Signs in Cities
}

\author{
Wei Liu \\ Foreign Language Department, Dalian Jiaotong University, Dalian, Liaoning Province, 116028, China
}

\begin{abstract}
Under the current cultural context of world economic globalization and social informationization, it is of profound and extensive realistic significance to explore the intertextuality of public signs translation in cities that facilitates the exchange and cooperation between Chinese and western cultures. This study focused on the translation of public signs from the perspective of intertextuality. Having started from texts and finally returned to texts, the work elaborated the unique correlation between intertextuality observation and translation studies. The character of cultural image was thus contained in the process of dynamic balance.
\end{abstract}

Keywords: Translation; Text; Public Signs

\section{Introduction}

Translation requires comprehensive analysis on source texts and more objective assessment of public signs in accordance with the aspects of originality, translation standard, retranslation phenomenon and translation definitive edition. In this way, the traditional close model of translation studies are broken through in order to radially penetrate language from the operating level to the dimensional discourse space [1]. Undoubtedly, intertextuality theory plays an irreplaceable role. However, the core of intertextuality precisely refers to the deconstruction of texts meaning that indicates the deficiency of meaning or the deconstruction of a new meaning. Therefore, it is the ultimate meaning deconstruction of source texts that reveals the real function of intertextuality theory in translation criticism.

\section{Linguistic theory in translation practices}

The word intertextuality was created by Julia Kristeva, a French post-structuralism literary critic, in her article Words, Dialogue and Fiction published in 1960s. Intertextuality here emphasizes mutual reference, response, contact, penetration and transfer among texts and focuses on the uncertainties and noncentrality of texts
${ }^{[2]}$. In Julia Kristeva's words, "each text is composed of mosaic quoted passage and is absorption and transformation of other cultural images [3]." The intertextuality theory of American Yale School Deconstruction, represented by Kristeva, Bart and Derrida, regards public signs as readable things and even extends them to the domain of social history and culture, namely large text concept. Intertextuality theory embraces all the readable and material social history and cultural reality that are beyond texts and opens them to the outside world ${ }^{[4]}$. Intertextuality here concretely refers to public signs, but more often, it tends to signify generalized texts. Two texts are actually interplaying with each other during the process when the translated meanings infinitely get close to the source meanings from the narrow sense to the broad sense. As Kristeva once said, "multiplex nodes can be used to reveal the unlimited connection between texts in intertextuality and languages ${ }^{[5]}$." The multiple unlimited connection here corresponds to some characteristics of intertextuality, and simultaneously attributes the differentiation and infiniteness of cultural images. Since texts show the infinite and open world with finite and closed form, the structure of text is never a chain but a finite way and function to transmit infiniteness and openness. Translators are demanded to get involved in texts and repeatedly communicate with the texts. In addition, they should also rewrite texts and continuously dispel structures and signs. Some methods, such as division, separation, criticism and intervention, can be used to pass down on the infiniteness and openness, and to reconstruct the target language texts. In that way, the translator in fact must have correctly understood and expressed the target language texts with their creativity. In translation, the relation between source texts and target texts is the same as that between pre-texts and created texts. Translators often intentionally reserve the lingering charm of translated texts, which is often delightedly accepted by readers. 


\section{Nature of texts}

Due to cultural estrangement, intertextuality correlation, the superlanguage factor in translation, is rarely known by people in other cultural systems, thus it becomes a hindrance to comprehension and communication. Translation has been regarded by some people as a practical activity of language-transference combined with reading and interpretation. While reading and interpretation actually belong to intertextuality activities, hence translation, as a combination of them both, can by no means be separated with intertextuality. For example, Kristeva straightforwardly takes changes and translation in intertextuality skills. More colloquially, the quotation and change of texts are intercultural even beyond the level of texts. As the results of intertextuality transformation, translated texts are based on the language and culture of source language. The characteristics of public signs translation determine its better accordance with that of the second level creation technique. In a sense, translated texts should be results of double reading and writing. The translated text is originally nontransparent text needing to be deciphered from source texts to translated texts, in other words, needing to be deconstructed and recreated from linguistic notation to translated texts. This text goes through an interlingual two-dimensional reading process, which is much too complicated. The process of translation aims to reallocate and exchange language parts with another novel form of language symbol so as to create a new text.

\section{Strategies for translation of public signs in cities}

The function of public signs is to persuade people to do or not to do something. Therefore, highly concentrated words should be used to attract attention and arouse abundant associative meanings ${ }^{[6]}$. In literary translation, some untranslatable phenomenon can be solved through supplementary specification or footnote, which can not be used in public signs translation since public signs are strictly restrained by time and space. Therefore, in order to achieve the greatest translation effectiveness, translators should always remember to reduce communication burdens of translated texts, and an appropriate use of intertextuality is also an effective way in translation.

Intertextuality on language level is always straightforward and obvious. It can be direct words quotation, clear bibliographic references, mutual reference among texts or even synonymous reference in the same text (here text generally refers to an independent discourse unit). In translation practices, if translators can have a discourse analysis in source texts with the help of intertextuality theory, they are able to deepen the understanding of source texts and better organize the structure of translated texts.

Compared with intertextuality on language level, intertextuality on cultural level is more indirect and obscure. Translators of public signs are supposed to handle the intertextuality of heterogenous culture. Sometimes, intertextuality can even cause unintelligibility of texts, which places higher requirements on translators, including the accumulation of local customs and practices, literary knowledge, national conditions under non-native cultural environment. Only through this accumulation can translators have their translated texts correspond with source texts. For translators, reading texts is actually a process of meanings generation. The understanding of readers is closely related to texts, social environment and subconsciousness. As nodal points of creation or recreation, readers of source texts and translated texts should jointly participate in the construction of intertextuality network. The quality of translated texts largely depends on both diachronic factors, like knowledge quality and language skills of readers, and their social cultural environment. For example, in western tourism English and tourists' commentary, the word "stay" is often used to express some Chinese words like Douliu, Tingliu or Xiata, usually coupled with customary collocation. For another example, in order to attract readers, tourism propagandas often use some contagious words rather than straightaway words. For instance, Shengyang can be enchanting or frustrating, vibrant or drab. But residents and visitors alike are prepared to tolerate or ignore the city's shortcomings for its endless ability to entertain, surprise and reward. The translated "wutong trees" is intended to remind readership of an exotic atmosphere and initiate reveries in use of a feeling of strangeness caused by puzzles. Translators try to preserve cultural images in original poems in such a way. In spite that the underlined words can be replaced by 
other frequent words, writers selected several words with rich connotation and emotion. So we can understand the characteristics and styles of wording in western tourism English. When equipped with intertextuality knowledge, translators should be careful of wording and phrasing. They are also supposed to translate source texts according to the practices of translated texts so as to generate emotional resonance of foreign readers. A Chinese word "wutong" was once translated as "the parasol trees" in a tourists attraction in Liaoning Province. This translation enters another cultural symbol system and needs to recreate the associative meaning. Source texts have intertextuality relation with other source texts while translators should establish new intertextuality relation with other translated texts. Faced with double intertextuality relation, translators should incline to translated texts. Therefore, the translation of the above public signs can be successful in dealing with cultural intertextuality phenomenon.

In the elevator hoistway of a hotel in Dalian, a sign reads that "please leave your precious things on reception desk". The intended meaning of this sign is to remind guests to keep their precious things in the locker. However, readers of translated texts can misunderstand the words as they might think they have run into a robbery. A sign in the luggage claim of an airport of Liaoning Province reads: "The luggage is everywhere". The correct translation should be "You should take good care of your luggage".

\section{Conclusion}

Whether it is direct transmission of local cultural images or distorted rewrite, intertextuality relation is always manipulated by translators. Therefore, translators should accurately grasp texts and intertextuality of social culture. Intertextuality of cultural images in translation has become the common wealth of human beings. Since its birth, intertextuality theory has exerted intensive influence on many humanistic disciplines like literature study, linguistic study, cultural study and philosophical study. This post modern text theory, combining with epistemology and methodology, is bound to have a deeper impact on translation studies in the two aspects of metaphysical epistemology and concrete methodology.

\section{Acknowledgements}

This study is supported by 2014 Annual Social Science Fund Project of Liaoning Province( No.2014lslktwx-06) Author: Liu Wei(1978-), Female, Master, Instructor.

\section{References:}

[1]. Schaffner,Christian and Kelley-Holmes,Helen.Ed.Cultural Functions of Translation. [M] Multilingual Matters Ltd,2005: 56.

[2]. Rojer T.Bell.Translation and Translating.Theory and Practice. [M] Longman,London and New York, 2001: 23-25.

[3]. Kristeva J . Word, Dialogue and the Novel [M] . New York: Columbia University Press, 1989: 37 .

[4]. Carford,J.C. A Linguistic Theory of Translation ,An Essay in Applied Linguistics. [M] Oxford University Press 2003:120.

[5]. Hatim, Bsil and Mason,Ian. Discourse and the Translation.[M]Longman Group UK Limited,2000: 89.

[6]. Basnet,Susan. Translation Studies(Revised Edition). [M] Methuuen Co.Ltd,1988:154. 